\title{
Machines as Engines of Growth
}

\author{
Joseph Zeira \\ The Hebrew University of Jerusalem and CEPR
}

January 2006

\begin{abstract}
This paper builds a model of growth through industrialization, where machines replace workers in a growing number of tasks. This enables the economy to experience long-run growth, as machines become servants of humans, and as their number grows unboundedly. The mechanism that drives growth is feedback between industrialization and wages. High wages provide incentives to use machines, while industrialization raises wages. The model shows that industrialization and growth take off only if the economy is productive enough. It also shows that monopoly power can stifle growth, as it lowers wages. Hence, a one-time increase in productivity, or a reduction of monopoly power can push economies from stagnation to industrialization.
\end{abstract}

JEL Classification: O14, O30, O40.

Keywords: Economic Growth, Industrialization, Technology.

Contact:

Joseph Zeira

Department of Economics

Hebrew University of Jerusalem

Mt. Scopus

Jerusalem 91905

Israel

E-mail: mszeira@mscc.huji.ac.il 


\section{Machines as Engines of Growth}

\section{Introduction}

During the last two hundred years global output per capita has grown by more than 8 . In the more developed countries output per capita has grown by twice as much. Such rapid growth has never been experienced before. It is therefore a new historical phenomenon of less than two centuries, which began with the industrial revolution, somewhere around 1820 , according to Maddison $(1995,2001)$. This paper is part of the ongoing effort to explain this new historical phenomenon. It focuses on industrialization and claims that growth has been made possible by creating machines that can perform various jobs that humans performed before, and replace workers. Most common examples are the steam engine, the car and the computer. Hence, machines have become our servants and have enabled us to increase production significantly. Unlike scarce humans, machines are available in increasing numbers, since they are easily created. Hence, productivity increases by using this ever growing army of servants, machines.

This paper builds a growth model that formalizes this idea. It describes a world where the final good is produced by many intermediate goods. Initially, each intermediate good is produced by workers and by some amount of capital, mainly tools and structures. A machine that replaces these workers can be invented, but this machine is costly as it increases the amount of capital in production. Hence, machines are used and there is demand for them only if their cost is lower than the alternative cost of production by labor. This leads to an important implication of this approach, namely that machines are invented and used only when wages are sufficiently high. Otherwise it does not pay to 
buy the machine and producers keep using labor instead. Hence, according to this approach, invention of such technologies depends on factor prices.

Growth therefore depends positively on wages, but it affects wages as well. If more intermediate goods are produced by machines, outputs of these intermediate goods increase. As a result, wages of workers in other sectors rise, since intermediate goods are complements. This creates a feedback between growth and wages, which can explain how growth continues over time. Note, that in this model replacing workers by machines does not substitute factors of production along the same technology, as in standard economic models, but requires a change in technology. This explains how capital can replace workers in this model without significantly diminishing marginal productivity.

The model shows that long-run growth depends on the overall productivity of the economy, which is fixed overtime. This productivity reflects geography, infrastructure and other factors. Productivity affects the growth rate through wages. If it is high enough, wages are high and growth goes on. If not, the process of industrialization and growth might come to a stop at some point. If overall productivity is very low, industrialization might not even take off at all. Hence, the fixed productivity affects positively the longrun rate of growth. Interestingly monopoly has an opposite effect on growth. If producers of intermediate goods have monopoly power, it raises profits on expense of wages, and lower wages deter growth.

These results can shed light on potential origins of the industrial revolution. One possibility is that the increase in productivity after the discovery of America pushed the global economy from a stagnant pre-industrial equilibrium to a new equilibrium, of ongoing industrialization. Another possibility is that the collapse of Feudalism, with its 
established monopoly rights, and the opening of free labor markets, led to the industrial revolution by raising the cost of labor. These two historical hypotheses, which are suggested by the model, are of course very preliminary and deserve more research.

The paper also includes an extension, which introduces in addition to the physical good a service good, which is not going through the process of replacing workers by machines. This extension of the model leads to an interesting result. Despite the decline of the share of labor income in industrial production, as capital replaces labor, the share of labor income in the overall economy does not fall, as is indeed observed in reality.

This paper is related to two lines of endogenous growth literature, one that focuses on capital accumulation, and one that studies technical progress. The first goes back to Solow (1956), but its recent versions are the AK models of Jones and Manuelli (1990) and Rebelo (1991). The second line of literature, R\&D based endogenous growth models, was developed by Romer (1990), Segestrom, Anant, and Dinopolous (1990), Grossman and Helpman (1991), Aghion and Howitt (1992) and Jones (1995, a, b). This paper contains elements of both, but also differs significantly from both. Growth is driven by capital accumulation as in AK models but capital accumulation involves continuous changes in the production function, namely innovations, as in the R\&D based models.

The main similarity to AK models is that the marginal productivity of capital is bounded from below. But there are two significant differences. The first is that this model presents micro-foundations to such a production function. The second is that in AK models growth is driven by profitability, while in this model it is driven by wages. As a result the effect of monopoly power is opposite in the two models. This paper also differs significantly from R\&D based growth models. First, the cost of using a new innovation is 
not only the cost of invention, but also the cost of the machine, in which the innovation is embedded. This leads to very different dynamics, especially with respect to scale, as shown in the paper. Second, this paper tries to answer a question left unanswered by R\&D models: how can innovations increase productivity? How can obscure scribbles of inventors increase productivity of millions of workers? This paper suggests that by inventing machines that perform jobs previously done by workers innovators invent servants that help us in production. This happens to be more than just an explanation to the content of innovations, but it also affects the dynamics of growth significantly.

The idea of innovations that substitute labor with capital has appeared before in Champernowne (1963) and in Habbakuk (1962). ${ }^{1}$ This idea is also modeled in Zeira (1998), but that paper studies a very different issue, of technology adoption and output differences across countries, assuming technical change is exogenous. ${ }^{2}$ The current paper uses this idea in a very different framework, of global growth, and adds to the analysis endogenous invention of technologies. ${ }^{3}$

The paper is constructed as follows. Section 2 presents the benchmark model. Section 3 describes industrialization and Section 4 examines the dynamics of long-run growth. Section 5 discusses the effect of monopoly power on growth. Section 6 examines the case of costly innovation. Section 7 presents possible explanations to the industrial revolution. Section 8 discusses the dynamics of the shares of labor and capital in income. Section 9 studies other issues, like divergence and energy prices. Section 10 summarizes and an Appendix contains mathematical proofs.

\footnotetext{
${ }^{1}$ Capital augmented technical progress appears already in Solow (1960) and other earlier works, but they do not use the idea of technology as substituting labor by capital.

2 That paper is more related to the literature on 'appropriate technologies'. See Basu and Weil (1998).

${ }^{3}$ Beaudry and Collard (2002) use a similar idea as well, in analyzing employment dynamics.
} 


\section{The Model}

This section describes the benchmark model of growth and industrialization. Consider a closed economy, which produces one final good, which is used both for consumption and for investment. The final good is produced by a continuum of intermediate goods, ordered on $[0,1]$. Production of the final good in period $t, Y_{t}$, is described by a CobbDouglas production function: ${ }^{4}$

$$
\log Y_{t}=\log a+\int_{0}^{1} \log x_{t}(i) d i
$$

where $x_{t}(i)$ is the amount of the intermediate good $i$ used in production in period $t$ and $a$ is a productivity parameter, which holds for the aggregate economy. It is later shown that this productivity parameter plays an important role in the dynamics of the model.

Each intermediate good can be produced by one of two potential technologies, pre-industrial (manual) or industrial. Both technologies operate in fixed proportions. In the pre-industrial technology one unit of the intermediate good $i$ is produced by $l(i)$ units of labor and $k(i)$ units of capital. Capital fully depreciates after one period of time, namely time units are long. Capital in this pre-industrial technology consists of structures and tools, but not machines. The industrial technology introduces a machine that can produce the same intermediate good. A machine that consists of $m(i)$ units of capital can replace the old technology and produce one unit of the intermediate good $i$. Depreciation is full under this technology as well. It is assumed that the invention of such a machine is costless, so that a machine is invented once there is demand for it. ${ }^{5}$

\footnotetext{
${ }^{4}$ Alternative production functions, like CES, yield the same results.

${ }^{5}$ The case of costly innovation is analyzed in Section 6.
} 
We next add two assumptions on the function $m$, which lead to the result of longrun growth. First, order the intermediate goods by increasing cost of machines, $m(i)$, and assume that:

$$
m(i) \underset{i \rightarrow 1}{\longrightarrow} \infty .
$$

Namely, machines required to produce intermediate goods, which are close to 1, become increasingly complicated and costly. In other words, some jobs, like a CEO, or an engineer, are very hard to replace by a machine. It is also assumed that this increasing complexity does not make overall industrialization too expensive, namely the sum of logarithms of machine costs over all potential machines is bounded:

$$
\int_{0}^{1} \log m(i) d i=\log b<\infty
$$

The parameter $b$, which is finite, is therefore defined by equation (3). This second assumption is necessary for long-run growth, as shown below. ${ }^{6}$ For the sake of simplicity assume that the functions $k, l$, and $m$ are all continuous.

Next describe individuals in this economy. Assume that there is a mass $L$ of identical individuals with infinite horizons. Each person supplies 1 unit of labor in each period and has the following utility from consumption:

$$
U=\sum_{t=0}^{\infty} \frac{\log \left(c_{t}\right)}{(1+\rho)^{t}}
$$

The use of logarithmic utility is for simplification only and the results of the paper hold for any utility function.

\footnotetext{
${ }^{6}$ Actually, if a CES production function is used in (1), instead of Cobb-Douglas, (3) is not required if the elasticity of substitution is greater than 1 .
} 


\section{Industrialization and Factor Prices}

The main decision facing producers is the choice of technology, namely whether to stick to the old pre-industrial technology or to industrialize. The decision depends on factor prices, since industrialization involves reduction of labor, but at the expense of purchasing more capital. Producers of $i$ adopt the new technology and industrialize in period $t$ if:

$$
R_{t} m(i) \leq R_{t} k(i)+w_{t} l(i),
$$

where $w_{t}$ is the wage rate and $R_{t}$ is the gross rental rate of capital or the gross interest rate, paid in period $t$ on capital invested in period $t-1$. Written differently, production of $i$ is industrialized if:

$$
\frac{m(i)-k(i)}{l(i)} \leq \frac{w_{t}}{R_{t}} .
$$

Thus, the set of intermediate goods produced by machines in period $t$, which is called the industrial set $I_{t}$, is equal to:

$$
I_{t}=\left\{i: m(i) \leq k(i)+\frac{w_{t}}{R_{t}} l(i)\right\} .
$$

Hence, the degree of industrialization depends crucially on the wage rate relative to the rate of return. Higher wages relative to the gross rate of return create an incentive to invent and use more technologies, as these enable reduction of costly labor input. Lower wages deter industrialization, as workers are inexpensive relative to costly machines.

Figure 1 describes the industrialization of the economy, namely the industrial set in period $t$, as described by equation (5). Clearly, as the ratio of factor prices $w_{t} / R_{t}$ rises, the industrial set $I_{t}$ increases. Note that if the factors' price ratio $w_{t} / R_{t}$ is very low, no 
intermediate good is industrialized, since $m(i)>k(i)$ for all $i$, so that the industrial set is empty. This is the case of a pre-industrialized economy, like the world prior to the industrial revolution. As is clear from this figure and from the analysis above, the degree of industrialization depends on the factor prices of labor and capital. We next turn to describe how these prices are determined.

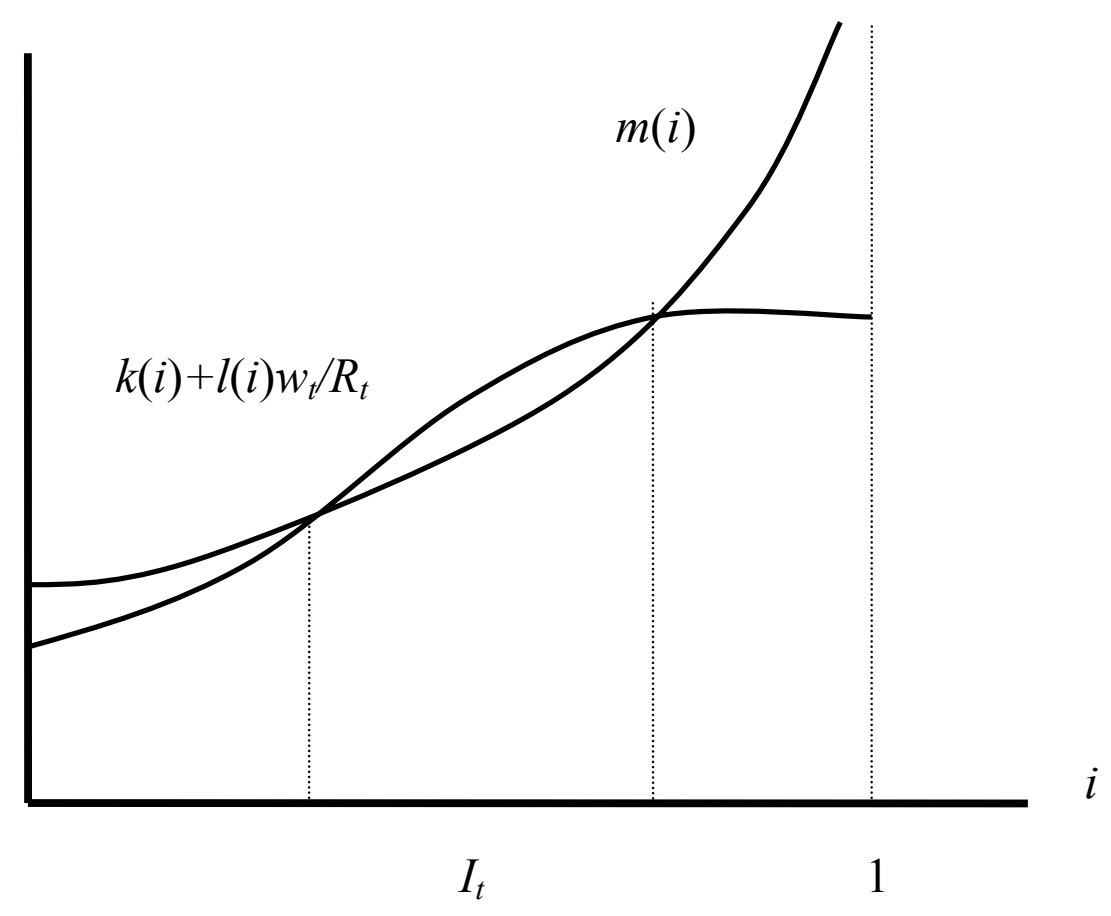

Figure 1

Perfect competition in the markets for intermediate goods leads to the following profit maximization condition:

$$
p_{t}(i)=\frac{\partial Y_{t}}{\partial x_{t}(i)}=\frac{Y_{t}}{x_{t}(i)} .
$$

This describes the demand for the intermediate good. Its supply is perfectly elastic due to fixed marginal productivity. Hence the price of each intermediate good is: 


$$
p_{t}(i)=\min \left\{R_{t} m(i), R_{t} k(i)+w_{t} l(i)\right\}=\left\{\begin{array}{l}
R_{t} m(i) \text { if } i \in I_{t} \\
R_{t} k(i)+w_{t} l(i) \text { if } i \notin I_{t} .
\end{array}\right.
$$

Substituting (7) in (6) and then in (1) we get the following relationship between the wage rate, the interest rate and the degree of industrialization:

$$
\begin{gathered}
\int_{0}^{1} \min \left\{\log \left[R_{t} m(i)\right], \log \left[R_{t} k(i)+w_{t} l(i)\right]\right\} d i= \\
=\int_{I_{t}} \log \left[R_{t} m(i)\right] d i+\int_{I_{t}^{c}} \log \left[R_{t} k(i)+w_{t} l(i)\right] d i=\log a .
\end{gathered}
$$

This equation defines the factor price frontier.

An alternative way to present equation (8) is to view the integral on the LHS as a function of the two factor prices, namely:

$$
H(w, R)=\int_{0}^{1} \min \{\log [R m(i)], \log [R k(i)+w l(i)]\} d i .
$$

It can be shown that $H$ is concave and increasing in both $w$ and $R$. From equation (8) it follows that the factor price frontier is defined by:

$$
H\left(w_{t}, R_{t}\right)=\log a .
$$

The factor price frontier can also be written as an explicit function: $w_{t}=h\left(R_{t}\right)$, where $h$ is defined by $H[h(R), R]=\log a$.

It is easy to show that $h$ is decreasing and convex. The next lemma shows that the gross rate of interest is bounded from below on the factor price frontier.

Lemma 1: The factor price frontier satisfies: $R \geq a / b$. Hence, as the wage $w$ goes to $\infty$, the gross interest rate $R$ goes to $a / b$.

Proof: In the Appendix. 


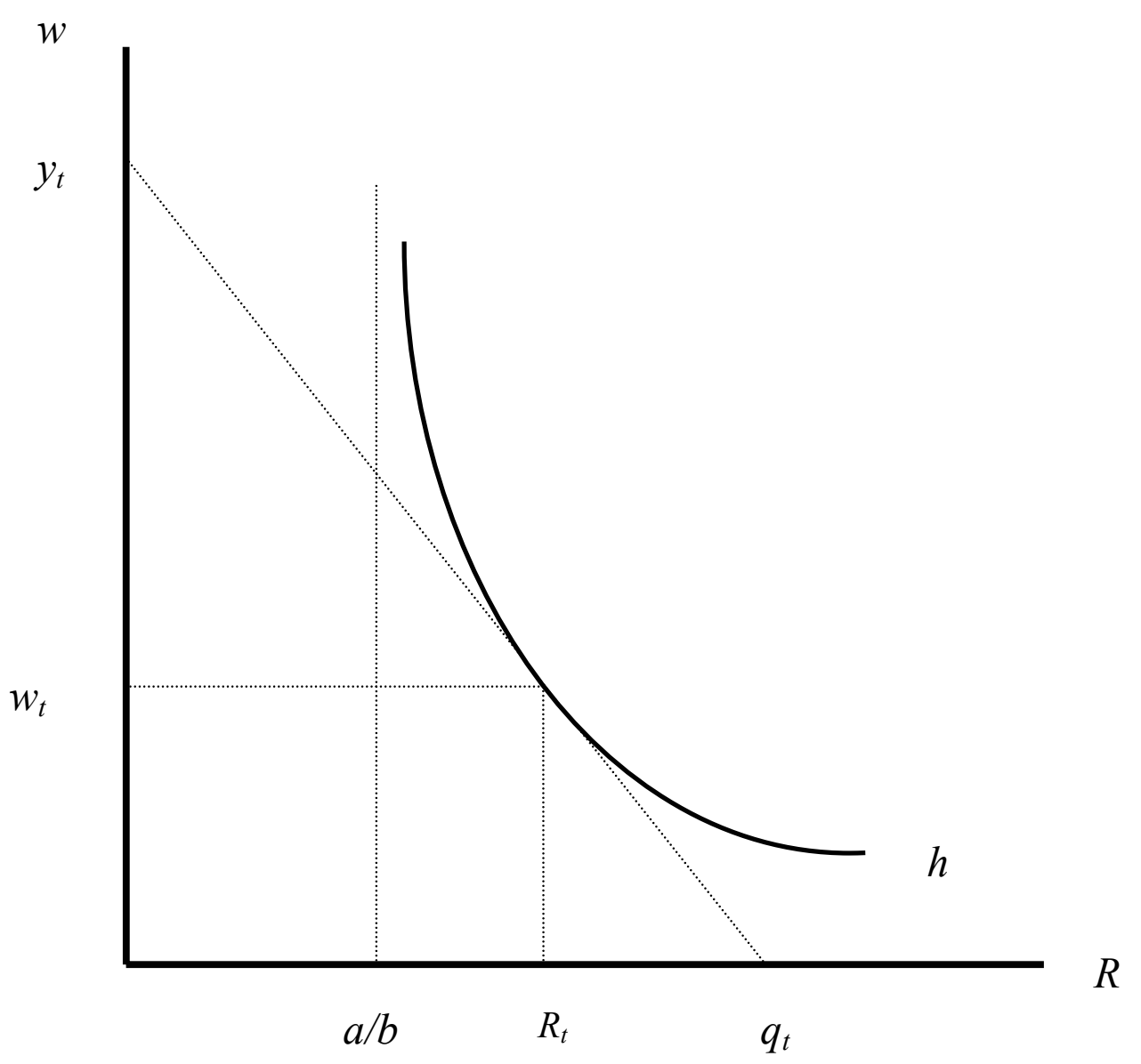

Figure 2

Figure 2 describes the factor price frontier, $w_{t}=h\left(R_{t}\right)$, based on Lemma 1. It also describes how the levels of output and capital per worker are determined by the factor price frontier. To see this we analyze the equilibrium conditions in the labor market and in the capital market. The labor market equilibrium condition is:

$$
L=\int_{I_{t}^{c}} l(i) x_{t}(i) d i=\int_{I_{t}^{c}} \frac{l(i) Y_{t}}{w_{t} l(i)+R_{t} k(i)} d i .
$$

The capital allocation condition is: 


$$
K_{t}=\int_{I_{t}} m(i) x_{t}(i) d i+\int_{I_{t}^{c}} k(i) x_{t}(i) d i=\int_{I_{t}} \frac{Y_{t} m(i)}{R_{t} m(i)} d i+\int_{I_{t}^{c}} \frac{Y_{t} k(i)}{w_{t} l(i)+R_{t} k(i)} d i .
$$

We next add to these two conditions the results of the following lemma.

Lemma 2: The function $H$ satisfies:

$$
\int_{I^{c}} \frac{l(i)}{w l(i)+R k(i)} d i=H_{w}
$$

and:

$$
\int_{I^{c}} \frac{k(i)}{w l(i)+R k(i)} d i+\int_{I} \frac{m(i)}{R m(i)}=H_{R}
$$

Hence: $\quad R H_{R}+w H_{w}=1$.

Proof: In the Appendix.

From equation (11) and Lemma 2 we derive the following equilibrium condition:

$$
L=Y_{t} H_{w}\left(w_{t}, R_{t}\right) .
$$

This condition determines the level of output $Y_{t}$ as a function of the factor prices. From the capital allocation condition (12) and from Lemma 2 we get:

$$
K_{t}=Y_{t} H_{R}\left(w_{t}, R_{t}\right) .
$$

Hence, the capital labor ratio is equal to: $k_{t}=K_{t} / L=H_{R} / H_{w}=-h^{\prime}\left(R_{t}\right)$. Namely, the capital labor ratio is the slope of the factor price frontier. To graphically describe output per worker, note that due to Lemma 2, total gross income is equal to gross output:

$$
w_{t} L+R_{t} K_{t}=Y_{t}\left(w_{t} H_{w}+R_{t} H_{R}\right)=Y_{t} .
$$

Hence output per worker can also be described by Figure 2:

$$
y_{t}=\frac{Y_{t}}{L}=w_{t}+R_{t} \frac{K_{t}}{L}=w_{t}+R_{t} k_{t} .
$$


Figure 2 also describes the output-capital ratio, which we denote by $q_{t}$ :

$$
q_{t}=\frac{y_{t}}{k_{t}}
$$

Clearly $q_{t}$ is increasing with $R_{t}$ and converges to $a / b$ as $R_{t}$ goes down to $a / b$.

\section{The Dynamics of Industrialization}

The dynamic solution of the model follows the two standard conditions of a representative agent economy. One is the first order condition of utility maximization:

$$
\frac{c_{t+1}}{c_{t}}=\frac{R_{t+1}}{1+\rho} .
$$

The second condition is the goods market equilibrium condition:

$$
c_{t}=y_{t}-k_{t+1}=w_{t}+R_{t} k_{t}-k_{t+1}=h\left(R_{t}\right)-R_{t} h^{\prime}\left(R_{t}\right)+h^{\prime}\left(R_{t+1}\right) \text {. }
$$

The dynamic Rational Expectations solution to these two dynamic equations, which satisfies the No-Ponzi-Game condition, is a saddle path that converges to a steady state. We next show that there are two dynamic cases.

In order to analyze the dynamics of this economy, where consumption can grow forever, we define a new variable, the ratio between consumption and capital:

$$
v_{t}=\frac{c_{t}}{k_{t}}
$$

Substituting in equations (16) and (17) we derive two dynamic equations of the system with the variables $v_{t}$ and $R_{t}$. The equation that describes the dynamics of $R$ is:

$$
\frac{k_{t+1}}{k_{t}}=\frac{-h^{\prime}\left(R_{t+1}\right)}{-h^{\prime}\left(R_{t}\right)}=\frac{y_{t}}{k_{t}}-v_{t}=q_{t}-v_{t} .
$$

The dynamics of $v$ are described by: 


$$
\frac{v_{t+1}}{v_{t}}=\frac{R_{t+1}}{1+\rho} \frac{k_{t}}{k_{t+1}}=\frac{R_{t+1}}{1+\rho} \frac{1}{q_{t}-v_{t}} .
$$

In order to analyze the dynamics of the economy, we draw the phase diagram of the system in Figures $3 \mathrm{a}$ and $3 \mathrm{~b}$. The curve $R_{t+1}=R_{t}$ is derived from (18) and is described by $v_{t}=q_{t}-1$ for $R_{t}>a / b$, which is an increasing curve, and also by the vertical line $R_{t}=a / b$. The curve $v_{t+1}=v_{t}$ is derived from (19) and is the solution to the following equation:

$$
v_{t}=q_{t}-\frac{R_{t+1}}{1+\rho}=q_{t}-\frac{R_{t+1}\left(R_{t}, v_{t}\right)}{1+\rho} .
$$

It can be shown that this curve has a smaller slope than the $R_{t+1}=R_{t}$ curve.

Next we differentiate between two cases. In the first case productivity is low, so that $a / b \leq 1+\rho$. This case is described in Figure 3a, where the two curves of the phase diagram intersect at $R_{t}=1+\rho$. The dynamic path is described by the saddle path in Figure 3a. Note that in this case the growth rate falls to zero at the steady state, since the steady state rate of interest is equal to $\rho$. Hence consumption does not grow at the steady state, and since $v$ is constant at the steady state, capital per worker $k$ and output do not grow as well. Therefore, this case describes an economy where industrialization and growth of output per capita come to a stop as the economy reaches the steady state. An even more extreme sub-case is when industrialization does not begin at all. This occurs when productivity $a$ is very small. This happens if the two curves in Figure 1 do not intersect at all. In this case the economy remains in a pre-industrialized equilibrium. 


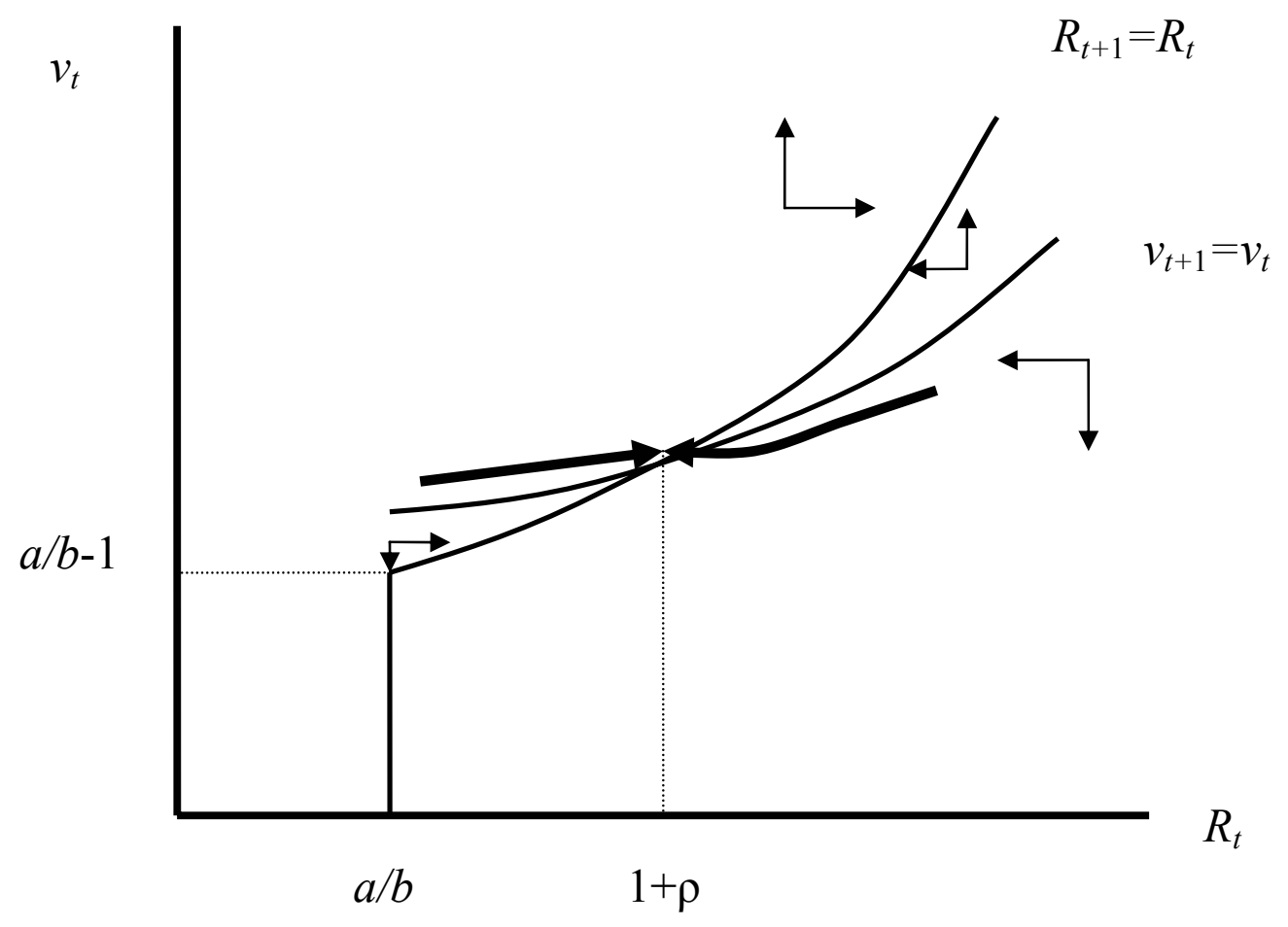

Figure 3a

The second case is when productivity $a$ is sufficiently high, so that $a / b>1+\rho$.

This case is described in Figure 3b, where the economy converges on a saddle path to the following steady state: $R^{*}=a / b$ and $v^{*}=\frac{a}{b} \frac{\rho}{1+\rho}$. Therefore, the economy experiences long-run growth. Formally, the rate of growth of consumption converges to $g$, where:

$$
g=\frac{a}{b(1+\rho)}-1>0
$$

Since $v_{t}$ converges to a finite number and so does $x_{t}$, it follows that both output and capital grow permanently and that their long-run growth rates are equal to $g$ as well. Hence, this model of machines that replace workers can generate long-run growth. 


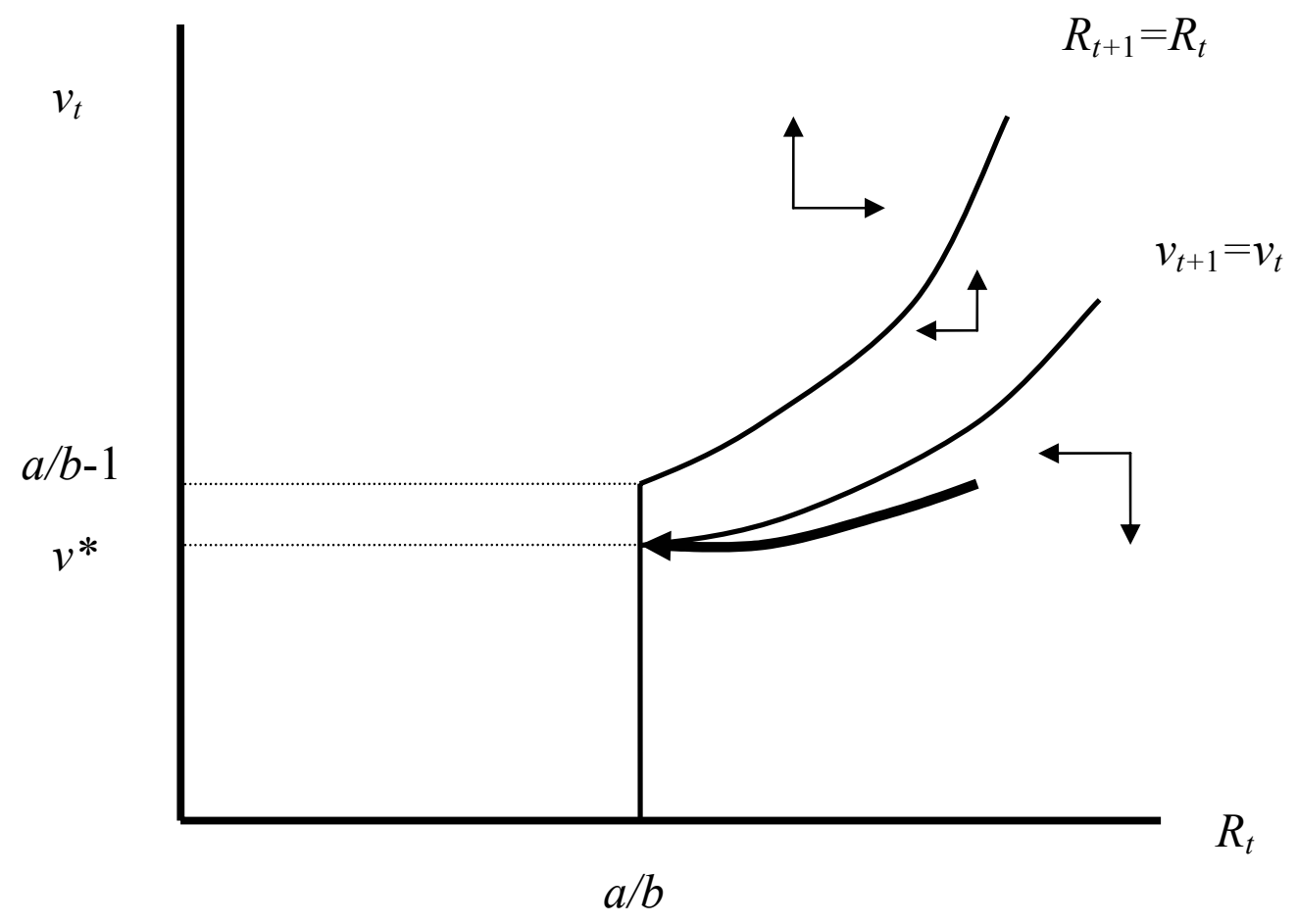

Figure $3 b$

We can therefore summarize the above discussion in the following Proposition.

Proposition 1: There is a unique equilibrium path. If $a>b(1+\rho)$ the economy grows forever and the rate of growth converges to $g$. If $a \leq b(1+\rho)$, growth peters out and the economy converges to a steady state without growth.

This model therefore shows that the long-run rate of growth depends crucially on the overall productivity of the economy $a$. A one-time shock to productivity can lead to increased growth over a long period of time and even to permanent growth. To gain a 
better understanding of this result we further analyze the aggregate production function in the next proposition, which also proves the optimality of the competitive equilibrium.

Proposition 2: Let $F\left(K_{t}, L\right)$ be the maximum amount of output that can be produced by $L$ workers and $K_{t}$ capital. Then: $Y_{t}=F\left(K_{t}, L\right)$. Namely, production is optimal in the market economy. Also, the marginal productivities of labor and capital are equal to $w_{t}$ and $R_{t}$, respectively. Furthermore, the intertemporal equilibrium is optimal as well.

Proof: In the Appendix.

Proposition 2 can help us better understand the strong dependency of dynamics on productivity $a$. The marginal productivity of capital, when technology is endogenous, is bounded from below by $a / b$. Hence, if this bound is sufficiently large, long-run growth prevails. In this respect the model is very similar to the AK models of Jones and Manueli (1990) and Rebelo (1991). But it also differs significantly from these AK models. First, it has a micro-model of technology and innovation, which generates the AK relation. Second, the mechanism through which the economy grows is very different. While in the AK models growth is driven by the high marginal productivity of capital, in this model it is driven by high wages. High productivity raises labor costs and increases the incentives to use more machines. Once these additional machines are used, wages rise by more, since intermediate goods cooperate in the production of the final good. That raises the incentive to invest in more costly machines and put them into use. And so the process of industrialization is rolling on, creating incentives for further industrialization at each step on the way. This difference between the two models is not just in the description of the 
mechanism of growth, but it also has significant implication, like the effect of monopoly power on growth, which is discussed in the next section.

\section{Monopolies, Wages and Growth}

In this section we deviate from perfect competition and examine what happens if producers of intermediate goods have monopoly power. This can reflect social norms, like Feudalism, or other causes. We assume that the monopoly power is exogenous and examine how it affects growth. Intuitively, the effect of monopoly power on growth should be negative, since monopoly power enables producers to reduce wages and that reduces growth in this framework. The rest of the section formalizes this insight.

Assume that producers of intermediate goods have a monopoly power so that they earn a profit, which equals a share $z$ of revenues. Such profits arise for example when there are $N$ producers of each intermediate good, who form an oligopoly. If they participate in a Cournot competition and if $N>1$, then in a symmetric equilibrium each producer earns a profit, which is equal to a share $z$ of revenues, where:

$$
z=\frac{1}{N} .
$$

If producers earn a profit of rate $z$ of revenues, the price of each intermediate good is:

$$
p_{t}(i)=\left\{\begin{array}{l}
\frac{w_{t} l(i)+R_{t} k(i)}{1-z} \text { if } i \notin I_{t} \\
\frac{R_{t} m(i)}{1-z} \text { if } i \in I_{t} .
\end{array}\right.
$$

Combining (21) with equation (6) and substituting in equation (1) we get the following factor price frontier: 


$$
\int_{0}^{1} \min \left\{\log \left[R_{t} m(i)\right], \log \left[R_{t} k(i)+w_{t} l(i)\right]\right\} d i-\log (1-z)=\log a .
$$

Hence, in a monopolistic economy the factor price frontier is affected not only by productivity $a$, but by the degree of monopoly power $z$ as well. As monopoly power increases the factor price frontier shifts to the left. It is clear from (22) that as wages rise to infinity, the gross rate of interest $R$ converges to:

$$
\frac{a}{b}(1-z)
$$

The solution of the rest of the model is the same as in Section 4, except that $a / b$ is replaced by $a(1-z) / b{ }^{7}$ Thus, the condition for long-run growth is more restrictive under monopoly:

$$
\frac{a}{b}(1-z)>1+\rho
$$

If this condition holds and the economy experiences long-run growth, its steady state growth rate is:

$$
g=\frac{a(1-z)}{b(1+\rho)}-1
$$

Hence, monopoly power impedes growth and it can even bar the economy from growing and keep it stagnant. This result is opposite to that of AK models, where higher profitability contributes to growth. The mechanism through which the monopoly effect operates in this model is by lowering wages, which is detrimental to growth. ${ }^{8}$

\footnotetext{
${ }^{7}$ Note that although agents are not identical under monopoly, as workers and producers earn different incomes, the dynamic equations of the model are the same. Since consumption dynamics are linear for each individual: $c_{t+1}=c_{t} R_{t+1}(1+\rho)^{-1}$, they can be aggregated across individuals. The goods market equilibrium condition is also the same: $k_{t+1}=y_{t}-c_{t}$.

${ }^{8}$ The effect of wages on growth is also studied recently by Saint-Paul (2005), but through its effect on consumption and demand.
} 


\section{Costly Innovations and the Effect of Scale}

While section 5 examines the differences between this model and the AK literature, this section compares this model with the other literature on endogenous growth, the R\&D based models. Similar to these models growth in this paper is also driven by new innovations. But the existing R\&D models focus only on the innovation cost of new technologies, while this paper emphasizes the capital cost of the machines within which the new technologies are embodied. So far the model has assumed for simplicity that the cost of innovation is zero. This section examines what happens if the cost of innovation is positive, so the comparison with R\&D based growth models becomes more transparent.

Consider the model presented in Section 2 with the following extension. Inventing a new machine is costly. The cost of innovation $I_{t}$ is assumed to be proportional to output per capita: ${ }^{9}$

$$
I_{t}=d \frac{Y_{t}}{L}
$$

For simplicity assume that a patent on innovation lasts only one period and in next periods the innovation becomes public knowledge. Hence, a machine $i$, which is invented in period $t-1$, costs $m(i)$ in future periods, but $m(i)+z(i)$ in the first period, namely when invested in period $t-1$. Due to competition among innovators the patent fee $z(i)$ for an invented machine is equal to:

$$
z(i)=\frac{I_{t-1}}{x_{t}(i)}=\frac{d Y_{t-1} / L}{Y_{t} / p_{t}(i)}=\frac{d p_{t}(i)}{\left(1+g_{t}\right) L}
$$

where $g_{t}$ is the growth rate at time $t$.

\footnotetext{
${ }^{9}$ This is of course a simplifying assumption. Alternative assumptions on cost, like wages, yield similar results.
} 
The price of the good in first period of invention is equal to:

$$
p_{t}(i)=R_{t} m(i)+R_{t} z(i) .
$$

Together with (24) this yields:

$$
z(i)=\frac{d R_{t}}{\left(1+g_{t}\right) L-d R_{t}} m(i) .
$$

Hence, a machine $i$ is introduced in period $t$ if:

$$
m(i) \frac{\left(1+g_{t}\right) L}{\left(1+g_{t}\right) L-d R_{t}} \leq k(i)+\frac{w_{t}}{R_{t}} l(i) .
$$

Equation (26) shows that with costly innovations there is a scale effect, and a larger scale $L$ can speed innovations and growth. But the scale effect in this model is diminishing, and as $L$ becomes large the scale effect becomes negligible and the model converges to the benchmark model from Section 2. Thus, the scale effect, which is so troubling in the original R\&D growth models, as shown by Jones (1995a), is much reduced here. The intuitive reason for that is straightforward. The cost of adopting an innovation is the sum of the cost of innovation and the cost of the physical machine in which the innovation is embodied. As scale increases the cost of innovation per user falls, but the capital cost of the machine remains unchanged. Hence, the benefit from scale is diminishing. Thus, scale can help economic growth, but only to a limited and diminishing extent.

\section{The Industrial Revolution}

The next three sections turn to some empirical implications of the model presented in this paper. This section examines how it can contribute to understanding the timing of the industrial revolution. We know from various sources, like Maddison (1995), that 
economic growth is a fairly recent phenomenon. It started somewhere in the beginning of the $19^{\text {th }}$ century and has been going steadily since then. It is also clear that growth is inherently related to the process of industrialization. Hence, this model of growth through industrialization seems suitable to study the industrial revolution. We should therefore ask what, according to this model, can push the economy from a pre-industrial equilibrium into industrialization.

Theoretically, the model offers two potential explanations, namely two exogenous events that could have triggered the industrial revolution. One is a rise in productivity $a$. If a rise in productivity takes it over the threshold of $b(1+\rho)$, it can start a process of long-run growth, as shown in Section 4. Thus, a rise in productivity could have triggered the industrial revolution, by increasing the cost of labor and creating incentives to invent machines and then use them all over the world. The second potential explanation to the industrial revolution according to this model could be a reduction in monopoly power. A stagnant economy can start industrialization and economic growth by reducing its monopoly power, as shown in Section 5. The reduction of monopoly power raises wages and creates incentives to industrialization. A third possible explanation could be an increase of scale, as the R\&D growth models claim and as shown in Section 6 of this paper. We focus in this section on the two first potential explanations, as they are more unique to this model.

What are the historical equivalents of an increase in productivity or of a reduction in monopoly power prior to the industrial revolution? Two possible answers come to mind. One possible rise in productivity in Western Europe could be the results of the discovery of America, that contributed to sea faring, to agriculture, through new plants 
and animals, and also by adding new territories, as described in Maddison (2001, p. 18). This discovery raised incomes and as a result the cost of labor increased as well. The rise in income after the discovery of America is documented in Maddison (2001). Between 1500 and 1820 income per capita in Western Europe, North America and Japan increased by more than $60 \%$. This gives some indication to an increase in productivity. Hence, the discovery of America, and the rise in productivity it brought, could be one potential trigger to the beginning of the industrial revolution.

The other historical development that could have triggered the industrial revolution was the decline of Feudalism. This process started in England with the Cromwell Revolution, was accelerated by the spread of Protestantism, and was further intensified with the French Revolution and the Napoleonic wars. During the $19^{\text {th }}$ century all over Europe the old system of control by few over land and production began crumbling down. Our model claims that these historical developments could also trigger and enable the industrial revolution.

The scope of this paper is of course not sufficient to seriously assess these two explanations to the beginning of the industrial revolution. It is possible that the two historical developments together contributed to it. It is also possible that the two events were not completely independent of one another, and the discovery of America contributed to the decline of Feudalism. Indeed, many writers have noted how closely related were the discovery of America, the collapse of Feudalism and the industrial revolution. ${ }^{10}$ The specific contribution of this paper is twofold. The first is to point at the causality from the two events to the industrial revolution, and the second is to point at the cost of labor as the main mechanism of effect.

\footnotetext{
${ }^{10}$ One example that comes to mind is of course the Communist Manifesto by Marx and Engels (1998).
} 


\section{The Shares of Labor and Capital}

The model of machines that replace workers in various stages of production yields some very realistic results, as shown above. It can explain how output can grow at high rates over a long period of time. It explains how the capital-labor ratio grows with output. But this model has one result which is in contrast with the empirical experience. According to the benchmark model the share of capital in output, which is equal to $R_{t} / q_{t}$, rises to 1 , while the share of labor in output falls gradually to zero. This has not happened in the last two centuries of economic growth, during which the shares of labor and capital have been quite stable at around $2 / 3$ and $1 / 3$ respectively. In this section we present an extension of the model that avoids this unrealistic result of diminishing share of labor, but maintains the other results of the model.

This section adds a second final good to the economy. This good is produced with capital and labor, but is assumed to have no technical progress and there are no machines that can help in its production. Many services fit this description, like education, arts and literature, personal services, etc. We therefore assume that there are two goods in the economy. One is a physical good that is produced as described in Section 2, and is used for consumption and investment. The other good is services, which is used for consumption only, and is produced by labor and capital in fixed proportions. One unit of services is produced by 1 unit of labor and $k^{*}$ units of capital. Utility is derived from consumption of the physical good $c$ and consumption of the service good $s$ :

$$
\sum_{t=0}^{\infty} \frac{\log c_{t}+\alpha \log s_{t}}{(1+\rho)^{t}}
$$

It is further assumed that the size of the population is fixed and equal to 1. 
Due to perfect competition in the labor market and to the linear technology of production of services, the price of the service good is $w_{t}+R_{t} k^{*}$. It follows that the demand for the service good satisfies:

$$
s_{t}=\frac{\alpha c_{t}}{w_{t}+R_{t} k^{*}} .
$$

In other words, the share of services in total consumption expenditure is $\alpha /(1+\alpha)$. The solution of the model leads to the following result:

Proposition 3: If productivity is sufficiently high, $a>b(1+\rho)$, there is sustainable longrun growth, as in the benchmark model. Also, the share of labor does not diminish to zero and it converges in the long-run to

$$
\frac{\alpha \rho}{1+\rho+\alpha \rho} \text {. }
$$

Proof: In the Appendix.

Note that if $\alpha=2$, so that the share of services in consumption is $2 / 3$, and if $\rho=3$, which is reasonable for a period of 30 years, we get that the share of labor in income converges to .6. Hence, the model, despite its great simplification, leads to results which resemble the stylized facts.

This extension of the model, therefore, avoids the result that the share of labor in income is diminishing to zero. It also has an additional interesting result. The share of labor in services increases continually. This has two intuitive explanations. One is that less and less workers are required in manufacturing, since they are replaced by machines. Second, the price of the service good, which is mainly the wage rate, rises by less than 
income, as shown in Figure 2 and as is clear intuitively. Hence, the demand for the service good increases and its production increases with it.

\section{Extensions}

This section discusses briefly three additional implications of the approach presented in the paper. First, it shows that the model can account not only for global growth, but also for the great divergence between regions since the industrial revolution. Second, it shows that energy prices can have a negative effect on the rate of economic growth. Note that energy is strongly related to this model, since replacing workers by machines also replaces human energy by thermal energy. Finally this section discusses the interpretation of TFP growth along the growth path in this model.

\subsection{Divergence between Regions}

So far this model has been used to describe global economic growth, namely it implicitly assumes that the closed economy is the world. Next we show that the model can be applied to explain large and growing differences across countries. As shown in many empirical studies, like Maddison (1995), Pritchett (1998), and Bourguignon and Morrison (2002), gaps between regions in the world have been increasing significantly since the beginning of the industrial revolution. This section shows how this model can account for such findings. ${ }^{11}$

Consider a world with two countries, or regions, $A$ and $B$. The two countries are similar except in their basic productivity $a$, and it is assumed that $a_{A}>a_{B}$. Furthermore, assume that:

\footnotetext{
${ }^{11}$ This sub-section extends the Zeira (1998) results by adding endogenous innovation.
} 


$$
\frac{a_{A}}{b}>1+\rho>\frac{a_{B}}{b} .
$$

Assume also that there is full capital mobility in the world. For simplicity assume that the intermediate goods are not tradable. The equilibrium in this economy is straightforward. Since the gross interest rate must satisfy: $R_{t}>a_{A} / b$, economy $A$ grows at a positive rate, which is higher than $a_{A} b^{-1}(1+\rho)^{-1}-1$. Economy $B$ is stagnant and gets stuck at a fixed level of wages and output per capita. ${ }^{12}$

This model can therefore account for very different regional growth performance, due to disparities in basic productivity. It is interesting to examine the data presented by Maddison (2001) with respect to two main regions. Region A is Western Europe, Western Offshoots and Japan. Region B is the rest of the world. In 1500 GDP per capita in A was 704, while GDP per capita in B was 535. Until 1820 GDP per capita in A rose to 1,130 , a rise of $60 \%$, while GDP per capita in B rose only to 573 , a rise of $7 \%$. This shows that at the outset of the industrial revolution the productivity difference between regions was already significant.

Finally, the model can be applied in a similar way to differences in cost of machines, in addition to differences in productivity. A country that faces a high cost of machines, due to import costs, has a higher $b$ and as a result growth slows down and may even stagnate completely. This result of the model is related to the empirical finding of Barro (1991) and other recent cross-country studies, who find that high costs of investment goods have a strong negative effect on growth.

\footnotetext{
${ }^{12}$ This equilibrium has one aspect which is not realistic, namely that consumption in both $A$ and $B$ grows at the same rate. This means that consumption in the stagnant economy has very low levels in period 0 . This result is due to the Ramsey framework and to having the same interest rate in both economies. One way to avoid this type of result is to assume instead an OLG economy with utility from bequests, and with minimum subsistence consumption.
} 


\subsection{Energy and Growth}

It is important to remember that machines that replace humans in various jobs require energy to operate. Hence machines that replace workers also replace the source of energy, from human energy to fossil energy, being either coal or oil. Thus, if we want to model the process of replacing workers by machines more realistically, we should add the energy requirements of machines as well. Next we extend the model in this direction in a very simplified way. Assume that when an intermediate good $i$ is produced by machines it requires a machine of size $m(i)$ and an input of energy of size $e(i)$. Assume that the price of energy is $q$, and that it is fixed over time. The condition for industrialization is similar to the benchmark model:

$$
R_{t} m(i)+q e(i) \leq R_{t} k(i)+w_{t} l(i) .
$$

Similarly the condition that determines the factor price frontier is:

$$
\int_{0}^{1} \min \left\{\log \left[R_{t} m(i)+q e(i)\right], \log \left[R_{t} k(i)+w_{t} l(i)\right]\right\} d i=\log a .
$$

It can be shown that the equilibrium is similar to the industrial growth equilibrium described above in Section 5. But the long run growth in this case depends crucially on the price of energy. If the price rises during the period of industrialization it can hold it down and even stop it. Hence, this model implies that the growth process is inherently bounded by the supply of energy on our planet. Of course, we can assume that the stock of energy on our planet is large enough, and that even when it is depleted we will be able to find other ways of harnessing solar energy to our use. But this brief analysis demonstrates that the price of energy is crucial for the process of industrialization and economic growth. 


\subsection{TFP Growth}

Economic growth is accompanied with the growth of the Solow residual, which is also called total factor productivity. In this paper it is hard to distinguish between capital accumulation and total factor productivity, since technologies are embodied in machines, in capital goods. We next examine directly total factor productivity as it is measured in all studies, and show that the measure is actually equal to:

$$
\begin{gathered}
\log Y-s_{K} \log K-s_{L} \log L=\log Y-s_{K} \log \left(\frac{s_{K} Y}{R}\right)-s_{L} \log \left(\frac{s_{L} Y}{w}\right)= \\
=\left[-s_{K} \log s_{K}-\left(1-s_{K}\right) \log \left(1-s_{K}\right)\right]+\log R+\left(1-s_{K}\right) \log \left(\frac{w}{R}\right) .
\end{gathered}
$$

Note that the first item on the RHS is the entropy of $s_{K}$ and is thus quite stable. So is the interest rate in our model, namely $\log R$. Hence, according to this formulation, most of the changes in TFP are driven by changes in wages. This means that TFP growth might measure not exogenous productivity, but rather rising wages. As shown in this model, these wages are also intricately related to the process of growth and technical progress, but the causalities might be very different.

\section{Summary}

This paper presents a model of industrialization, and describes it as a process of inventing new machines that replace workers in a growing set of tasks. In this process the wage rate plays a critical role. Wages serve as an incentive for adopting new technologies. But wages are also affected by technologies, since performance of some tasks by machines raises wages of workers, who perform the remaining tasks, due to higher marginal productivity. This feedback between wages and technology is the main mechanism that 
drives the results of this paper. It explains how the growth process can continue for long periods, it explains how growth is so sensitive to productivity, and it also explains why monopoly deters growth.

Finally, it is time to briefly discuss the type of innovations in this paper, namely machines that replace human labor. Although this is only one specific type of innovation, it can be shown to be quite common and general. Even an innovation that replaces a machine by a better machine also enables the workers operating it to use less labor in production. Furthermore, even innovations of new consumption goods tend to replace labor this way or the other. A dishwasher, TV dinner, radio, cinema, all replace labor, either at home, or in other locations. We do not have to go back to in history to the Ludites, to realize that new machines that replace human labor have had a central role in economic growth since the industrial revolution. This paper shows that embodying this insight into growth theory can help us significantly in understanding the growth process. 


\section{Appendix}

\section{Proof of Lemma 1:}

Note that (8) can be rewritten as:

$$
\log R_{t}=\log a-\int_{0}^{1} \min \left\{\log m(i), \log \left[k(i)+\frac{w_{t}}{R_{t}} l(i)\right]\right\} d i .
$$

The integral on the RHS of (A1) is increasing with the ratio of factor prices $w_{t} / R_{t}$. Due to our assumptions on $m_{i}$ this integral is also bounded, since:

$$
\int_{0}^{1} \min \left\{\log m(i), \log \left[k(i)+\frac{w_{t}}{R_{t}} l(i)\right]\right\} d i \leq \int_{0}^{1} \log m(i) d i=\log b<\infty .
$$

Furthermore, it is clear that as the ratio of factor prices rises, the set of industrialized intermediate goods $I$ increases and converges to $[0,1]$. Hence, the integral converges to the upper bound, namely to $\log b$. As is clear from (A1), as the wage rate rises to $\infty, \log R$ converges to $\log a-\log b$. As a result $R$ is bounded by and converges to $a / b$. QED.

\section{Proof of Lemma 2:}

The function $H$ can also be written as:

$$
H(w, R)=\min _{I}\left\{\int_{I} \log [R m(i)] d i+\int_{I^{c}} \log [w l(i)+R k(i)] d i\right\} .
$$

Using the envelope theorem we get:

$$
H_{w}=\int_{I^{c}} \frac{l(i)}{w l(i)+R k(i)} d i
$$

and similarly for $H_{R}$.

QED. 


\section{Proof of Proposition 2:}

Maximum output $Y=F(K, L)$ is defined by:

(A2) $\log Y=\max _{I, x(i)}\left\{\log a+\int_{0}^{1} \log x(i) d i: \int_{I} m(i) x(i) d i+\int_{I^{c}} k(i) x(i) d i=K, \int_{I^{c}} l(i) x(i) d i=L\right\}$.

The maximization of (A2), using two shadow prices, $z_{1}$ and $z_{2}$ for the two constraints respectively, yields the following first order conditions:

$$
\frac{1}{x(i)}=z_{1} m(i)
$$

if $i \in I$, and

$$
\frac{1}{x(i)}=z_{1} k(i)+z_{2} l(i)
$$

if $i \notin I$, and

$$
z_{1} m(i)=z_{1} k(i)+z_{2} l(i)
$$

at the border points between $I$ and $I^{c}$. Define $R=z_{1} Y$ and $w=z_{2} Y$. By substituting (A2), (A3) and (A4) into the production function (1) we get:

$$
H(w, R)=\log a .
$$

Hence, the optimal allocation of labor and capital between the intermediate goods is the equilibrium allocation and output is optimal.

Note that:

$$
\frac{d \log Y}{d K}=M P K \frac{1}{Y}=z_{1}=\frac{R}{Y}
$$

Hence the marginal productivity of capital is equal to $R$ and similarly the marginal productivity of labor is equal to $w$.

A central planner maximizes output in each period and intertemporally maximizes: 


$$
\sum_{t=0}^{\infty} \frac{\log c_{t}}{(1+\rho)^{t}}=\sum_{t=0}^{\infty} \frac{\log \left(y_{t}-k_{t+1}\right)}{(1+\rho)^{t}} .
$$

It can be shown that the first order conditions of this maximization are equal to the dynamic conditions of the competitive equilibrium. Hence, the competitive equilibrium is optimal.

QED.

\section{Proof of Proposition 3:}

Note first that from utility maximization we get the first order condition:

$$
\frac{c_{t+1}}{c_{t}}=\frac{R_{t+1}}{1+\rho},
$$

so that the long run growth of consumption is:

$$
g=\frac{a / b}{1+\rho}-1>0 .
$$

Denote by $K$ the amount of capital in production of the physical good. Then the rate of growth of $K$ is:

$$
\frac{K_{t+1}}{K_{t}}=\frac{Y_{t}-c_{t}-s_{t} k^{*}}{K_{t}}=q_{t}-\frac{c_{t}}{K_{t}}-\frac{s_{t} k^{*}}{K_{t}} .
$$

Since $q_{t}$ converges to $a / b$ and since $s$ is bounded by 1 , it follows that the rate of growth of capital must converge to that of consumption. Hence the ratio between consumption of the physical good and capital in its production converges to:

$$
\frac{\rho a}{b(1+\rho)} \text {. }
$$

Second, note that the amount of labor in production of the physical good is no longer equal to the overall supply of labor. Due to (28) this amount of labor is equal to: 


$$
L_{t}=1-s_{t}=1-\frac{\alpha c_{t}}{w_{t}+R_{t} k^{*}}
$$

From equation (A7) and from Figure 2 we get:

$$
L_{t}=1-s_{t}=1-\frac{\alpha c_{t}}{k_{t}\left(q_{t}-R_{t}\right)+R_{t} k^{*}}=1-\alpha \frac{c_{t}}{K_{t}} \frac{L_{t}}{q_{t}-R_{t}+R_{t} k^{*} / k_{t}} .
$$

Since $c / K$ converges to a finite number, since $q-R$ converges to zero, and so is $k^{*} / k$, it therefore follows that $L_{t}$ converges to zero as the economy grows. Hence, the share of labor in production of the physical good converges to zero, while the share of labor in production of services increases continuously to 1 . The amount of services $s$ converges to 1 as well.

We next calculate the ratio between labor income and capital income:

$$
\frac{w_{t}}{R_{t} K_{t}+s_{t} R_{t} k^{*}}=\frac{\alpha c_{t} / s_{t}-R_{t} k^{*}}{R_{t} K_{t}+s_{t} R_{t} k^{*}} \underset{t \rightarrow \infty}{\longrightarrow} \frac{\alpha c}{s R K}=\frac{\alpha \rho}{1+\rho} .
$$

Hence the share of labor in total income converges to:

$$
\frac{\alpha \rho}{1+\rho+\alpha \rho}
$$

The share of labor therefore does not diminish to zero.

QED. 


\section{References}

Aghion, Philippe, and Howitt, Peter. "A Model of Growth through Creative Destruction," Econometrica, Vol. 60 (2), March 1992, p. 323-351.

Aghion, Philippe, and Howitt, Peter. Endogenous Growth Theory. Cambridge, MA: MIT Press, 1998.

Barro, Robert j. "Economic Growth in a Cross Section of Countries," Quarterly Journal of Economics, 106 (1991), 407-443.

Barro, Robert J., and Sala-i-Martin, Xavier. Economic Growth. New York: McGraw Hill, 1995.

Basu, Susantu, and Weil, David N. "Appropriate Technology and Growth," Quarterly Journal of Economics, 113 (1998), 1025-1054.

Beaudry, Paul, and Collard, Fabrice. "Why Has the Employment-Productivity Tradeoff Among Industrialized Countries Been So Strong?" NBER Working Paper No. 8754, 2002.

Bourguignon, François, and Morrison, Christian. "Inequality Among World Citizens: 1820-1992," American Economic Review, Vol. 92, Sep. 2002, p. 727-744.

Champernowne, David. "A Dynamic Growth Model Involving a Production Function," in F.A. Lutz and D.C. Hague, eds., The Theory of Capital (New York: Macmillan, 1963).

De Long, Bradford J. "Productivity and Machinery Investment: A Long-Run Look, 18701980," Journal of Economic History, LIII (1992).

Grossman, Gene M. and Helpman, Elhanan. Innovation and Growth in the Global Economy. Cambridge, MA: MIT Press, 1991.

Habbakuk, H. J. American and British Technology in the Nineteenth Century. Cambridge: Cambridge University Press, 1962.

Jones, Charles I. "Time Series Tests of Endogenous Growth Models," Quarterly Journal of Economics, Vol. 110 (2), May 1995 (a), p. 495-525.

Jones, Charles I. "R \& D-Based Models of Economic Growth," Journal of Political Economy, Vol. 103, August 1995 (b), p. 759-784.

Jones, Charles I. and Williams, John C. "Too Much of a Good Thing? The Economics of Investment in R\&D," Journal of Economic Growth, Vol. 5, March 2000, p. 65-85. 
Jones, Larry, and Manuelli, Rodolfo. "A Convex Model of Equilibrium Growth: Theory and Implications," Journal of Political Economy, Vol. 98, 1990, p. 1008-1038.

Maddison, Angus. Monitoring the World Economy 1820-1992. Paris, France: OECD, 1995.

Maddison, Angus. The World Economy: A Millenial Perspective. Paris, France: OECD, 2001.

Marx, Karl, and Engels, Frederick. The Communist Manifesto. London: Verso, 1998.

Pritchett, Lant. "Divergence, Big Time," Journal of Economic Perspectives, Vol. 11, Summer 1997, p. 3-17.

Rebelo, Sergio. "Long Run Policy Analysis and Long Run Growth," Journal of Political Economy, Vol. 99, June 1991, p. 500-521.

Romer, Paul M. "Endogenous Technical Change," Journal of Political Economy, Vol. 98, October 1990, p. S71-S102.

Saint-Paul, Gilles. "Distribution and Growth in an Economy with Limited Needs," Economic Journal, forthcoming, 2005.

Segestrom, Paul S., Anant T.C.A. and Dinopoulos, Elias. "A Schumpeterian Model of the Product Life Cycle," The American Economic Review, Vol. 80 (5), December 1990, p. 1077-1091.

Solow, Robert M. "A Contribution to the Theory of Economic Growth," Quarterly Journal of Economics, 71 (1956), 65-94.

Solow, Robert M. "Technical Change and the Aggregate Production Function," Review of Economics and Statistics, 39 (1957), 312-320.

Solow, Robert M. "Investment and Technical Progress," in Kenneth J. Arrow, Samuel Karlin and P. Suppes, eds., Mathematical Methods in the Social Sciences (Stanford: Stanford University Press, 1960).

Zeira, Joseph. "Workers, Machines and Economic Growth," Quarterly Journal of Economics, 113 (1998), 1091-1113.

Zuleta, Hernando. "Why Factor Income Shares Seem to be Constant?" mimeo, 2003. 